S. E. Ozanne $\cdot$ C. B. Jensen $\cdot$ K. J. Tingey $\cdot$

H. Storgaard $\cdot$ S. Madsbad $\cdot$ A. A. Vaag

\title{
Low birthweight is associated with specific changes in muscle insulin-signalling protein expression
}

Received: 30 September 2004 / Accepted: 25 October 2004 / Published online: 24 February 2005

(C) Springer-Verlag 2005

\begin{abstract}
Aims/hypothesis: People with low birthweight have an increased risk of developing type 2 diabetes mellitus in adulthood. The mechanistic basis of this phenomenon is not known. Here we investigate the effect of early growth restriction on the expression of insulin-signalling proteins in skeletal muscle in a human cohort and a rat model. Methods: We recruited 20 young men with low birthweight (mean birthweight $2702 \pm 202 \mathrm{~g}$ ) and 20 age-matched control subjects (mean birthweight $3801 \pm$ $99 \mathrm{~g})$. Biopsies were obtained from the vastus lateralis muscle and protein expression of selected insulin-signalling proteins was determined. Rats used for this study were male offspring born to dams fed a standard $(20 \%)$ protein diet or a low $(8 \%)$ protein diet during pregnancy and lactation. Protein expression was determined in soleus muscle from adult offspring. Results: Low-birthweight subjects showed reduced muscle expression of protein kinase $\mathrm{C}(\mathrm{PKC}) \zeta, \mathrm{p} 85 \alpha, \mathrm{p} 110 \beta$ and GLUT4. PKC $\zeta$, GLUT4 and p85 were also reduced in the muscle of rats fed a low-protein diet. Other proteins studied were unchanged in low-birthweight humans and in rats fed a low-protein diet when compared with control groups. Conclusions/interpretation: We found decreased expression of specific insulin-signalling proteins in low-birth-
\end{abstract}

\author{
S. E. Ozanne · K. J. Tingey \\ Department of Clinical Biochemistry, University of Cambridge, \\ Cambridge, UK \\ C. B. Jensen · H. Storgaard · A. A. Vaag \\ Steno Diabetes Center, \\ Gentofte, Denmark \\ S. Madsbad \\ Hvidovre University Hospital, \\ Hvidovre, Denmark \\ S. E. Ozanne $(\bowtie)$ \\ Department of Clinical Biochemistry, Addenbrooke's Hospital, \\ Level 4, \\ PO Box 232 Cambridge, CAMBS, CB2 2QR, UK \\ e-mail: seo10@cam.ac.uk \\ Tel.: +44-1223-762636 \\ Fax: +44-1223-330598
}

weight subjects compared to controls. These changes precede the onset of impaired glucose tolerance. The similarity of protein expression profile in the men with low birthweight compared to that of the offspring of rats fed a low-protein diet suggests that the rodent model is an accurate representation of the human situation. It also provides a potential mechanistic explanation as to why the fetal environment plays an important role in determining risk of developing type 2 diabetes.

Keywords Growth restriction · Insulin-signalling · Low birthweight . Type 2 diabetes

Abbreviations ECL: Enhanced chemiluminescence . GSK: Glycogen synthase kinase - LP: Low protein PI: Phosphatidylinositol - PKC: Protein kinase C

\section{Introduction}

Many epidemiological studies have revealed that there is a relationship between low birthweight and the subsequent development of type 2 diabetes, insulin resistance and the metabolic syndrome in a range of populations worldwide [1]. However, the mechanistic basis of this relationship is not known and the relative roles played by genetic and environmental factors, and the importance of the interaction between the two, remain the subject of much debate.

Mutations in the glucokinase gene have been identified, which are associated with a reduced birthweight and the development of maturity-onset diabetes of the young [2]. However, these are rare, and extensive genome-wide scans have thus far failed to identify universal diabetes susceptibility genes/polymorphisms.

The importance of environmental factors has been demonstrated by a number of studies in humans. Our studies of twins in Denmark [3] showed that in monozygotic twin pairs who were discordant for diabetes, the diabetic twin had a significantly lower birthweight than the normoglycaemic twin. Similar findings were observed in Italian twins [4]. In addition, studies of individuals exposed in 
utero to famine during the Dutch Hunger Winter have revealed that poor maternal nutrition, especially during the last trimester of pregnancy, leads to growth restriction of the fetus and is associated with poor glucose tolerance and insulin resistance [5].

To determine whether type 2 diabetes and the metabolic syndrome can be a long-term consequence of environmentally induced poor early growth, we have developed an animal model of intrauterine and early-life growth restriction [6]. The research strategy for this model included definition of the expression of molecules involved in the insulin-signalling pathway, since insulin resistance is a defining characteristic of type 2 diabetes and the metabolic syndrome. This molecular characterisation demonstrated that insulin receptor expression is not altered in muscle or adipose tissue from old adult offspring that had been growth-restricted at birth, suggesting that, as in the human situation, the molecular basis of the insulin resistance is a post-receptor defect. Two insulin-signalling molecules were expressed at dramatically reduced levels in the offspring with early growth restriction, namely the atypical protein kinase $\mathrm{C}$ (PKC), PKC $\zeta$ [7] and the $\mathrm{p} 110 \beta$ subunit of phosphatidylinositol (PI) 3-kinase [8,9]. These proteins are both known to be important in mediating the metabolic actions of insulin $[10,11]$.

We recently found reduced insulin-stimulated wholebody glycolysis [12] and muscle (forearm) glucose uptake [13] in 19-year-old lean and otherwise healthy Danish men with low birthweights as compared with matched control subjects whose birthweights were in the upper normal range. Our finding supports the notion that low birthweight is a significant pre-diabetic condition (or marker) in the western Caucasian population, with muscle insulin resistance representing an (or the) earliest detectable defect of metabolism. Understanding the molecular mechanisms that underlie muscle insulin resistance in young low-birthweight subjects could therefore provide important insight into the origin of type 2 diabetes. No studies to date have investigated the expression of components of the insulin-signalling pathway proteins in control and low-birthweight humans. We therefore sought to determine whether early growth restriction in humans is associated with the same molecular fingerprint in the insulin-signalling pathway as that which we established in our animal model of early growth restriction.

\section{Subjects, materials and methods}

Participants The study protocol was reviewed and approved by the regional ethical committee and procedures were performed according to the principles of the Helsinki declaration. The clinical characteristics of the subjects are presented in Table 1. The Danish Birth Registry was used to select 40 singleton men, who were born at term in 1980 in Copenhagen County. These men were selected according to birthweight, with 20 of them having birthweights below the 10th percentile and 20 having birthweights in the 50-75th percentile. Importantly, insulin resistance in
Table 1 Characteristics of control and low-birthweight men

\begin{tabular}{|c|c|c|}
\hline & Control & Low birthweight \\
\hline Age (years) & 19 & 19 \\
\hline Weight (kg) & $74.7 \pm 2.9$ & $73.6 \pm 1.9$ \\
\hline Height $(\mathrm{cm})$ & $181.7 \pm 4.8$ & $178.5 \pm 0.9 *$ \\
\hline BMI $\left(\mathrm{kg} / \mathrm{m}^{2}\right)$ & $22.6 \pm 0.8$ & $23.1 \pm 0.6$ \\
\hline Waist-to-hip ratio & $0.81 \pm 0.01$ & $0.82 \pm 0.01$ \\
\hline Fat $\operatorname{mass}_{\mathrm{DXA}}(\mathrm{kg})$ & $15.6 \pm 1.5$ & $15.6 \pm 1.5$ \\
\hline Lean body mass $\mathrm{DXA}(\mathrm{kg})$ & $56.9 \pm 1.6$ & $54.9 \pm 1.0$ \\
\hline Fasting plasma glucose $(\mathrm{mmol} / \mathrm{l})$ & $5.4 \pm 0.1$ & $5.6 \pm 0.1 *$ \\
\hline 2-h post-load glucose $(\mathrm{mmol} / \mathrm{l})$ & $5.3 \pm 0.2$ & $5.9 \pm 0.2$ \\
\hline f-p LDL cholesterol (mmol/l) & $2.16 \pm 0.1$ & $2.37 \pm 0.1$ \\
\hline f-p HDL cholesterol (mmol/l) & $1.31 \pm 0.05$ & $1.16 \pm 0.1$ \\
\hline f-p triglycerides $(\mathrm{mmol} / \mathrm{l})$ & $0.92 \pm 0.1$ & $1.09 \pm 0.1$ \\
\hline
\end{tabular}

$f-p$ fasting plasma $* p<0.05$

the pathway of glycolysis at the whole-body level, as well as according to muscle glucose uptake across the forearm, had been found and reported in this population previously $[12,13]$. Of the study participants, none had a family history (parents, grandparents) of diabetes, hypertension or ischaemic heart disease. None of them were receiving medication known to affect glucose homeostasis. Although the mean fasting plasma glucose concentration was statistically significantly elevated in the low-birthweight group (Table 1), all study participants had normal glucose tolerance after a standard 75 -g oral glucose tolerance test, according to the World Health Organization criteria. Height was determined as the mean of three measures by a stadiometer, and weight was determined using a manual scale measured weight. Waist-to-hip ratio was measured at the level of the umbilicus and greater trochanters, and lean as well as total fat mass were measured by a dual-energy X-ray absorptiometry scan. Written informed consent was obtained from the participants. Plasma glucose was measured at the bedside by an automated glucose oxidase method (Glucose Analyzer 2). Fasting plasma insulin and C-peptide concentrations were measured by the AutoDELPHIA automatic immunoassay system (Wallac Oy, Turku, Finland).

Muscle biopsy The participants reported to the laboratory at 08.00 hours after a 10 -h overnight fast. Muscle biopsies were obtained from the vastus lateralis muscle during local anaesthesia after 2 hours rest using a modified Bergstrom needle. Biopsies were immediately blotted free of blood, frozen immediately in liquid nitrogen and stored for later analysis at $-80^{\circ} \mathrm{C}$. The participants were instructed to abstain from strenuous physical activity and alcohol and to consume a diet rich in carbohydrate at least $48 \mathrm{~h}$ before the excision of muscle biopsies.

Animals All procedures involving animals were conducted under the British Home Office Animals Act, 1986. Wistar rats were bred locally at a designated animal unit of the University of Cambridge, Cambridge, UK. Virgin female 
Wistar rats used for the study were housed individually and were maintained at $22^{\circ} \mathrm{C}$ on a 12 -h light/12-h dark cycle. The animals were mated and day 0 of gestation was taken as the day on which vaginal plugs were expelled. The rats were fed a diet containing $20 \%$ protein $(n=8)$ or an isocaloric diet containing $8 \%$ protein $(n=8)$ during pregnancy and lactation The composition and source of the diets was as described by Snoeck et al. [14].

Spontaneous delivery occurred on day 22 of pregnancy and litters were subsequently reduced randomly to a standard litter size of 8 pups per mother. At 21 days of age, pups were weaned on to a $20 \%$ protein diet or a lowprotein (LP) diet. Rats used for this study were 15-monthold males ( $n=8$ control and $n=8$ LP offspring). Rats were fasted overnight, killed by $\mathrm{CO}_{2}$ inhalation and cervical dislocation. The soleus muscle, subcutaneous fat and epididymal fat were removed, snap-frozen and stored at $-80^{\circ} \mathrm{C}$ prior to analysis.

Chemicals and antibodies Analytical grade chemicals were obtained from Sigma Chemical or BDH Chemicals (both Dorset, UK) unless specified otherwise. Rabbit antipeptide antibodies against glycogen synthase kinase (GSK) $3 \alpha, \operatorname{GSK} 3 \beta, \mathrm{p} 110 \beta, \mathrm{PKC} \zeta$ and insulin receptor $\beta$ subunit, and mouse anti-peptide antibodies against PGC1 were obtained from Santa Cruz Biotechnology (Santa Cruz, CA, USA). Rabbit anti-peptide antibody against $\mathrm{p} 85$ and sheep anti-peptide antibody against Aktl were from Upstate Biotechnology (Lake Placid, NY, USA). The rabbit antibody against GLUT4 was purchased from Abcam (Cambridge, UK) and the rabbit antibody against aP2 was a kind gift from Professor D. Bernlohr, University of Minnesota, USA.

Analysis of human muscle protein expression Muscle specimens were extracted in ice-cold solubilisation buffer ( $50 \mathrm{mmol} / 1 \mathrm{HEPES}, 150 \mathrm{mmol} / \mathrm{l}$ sodium chloride, $1 \%$ Triton $\mathrm{X}-100,1 \mathrm{mmol} / \mathrm{l}$ sodium orthovanadate, $30 \mathrm{mmol} / 1$ sodium fluoride, $10 \mathrm{mmol} / 1$ sodium pyrophosphate, $10 \mathrm{mmol} / 1$ EDTA, $0.5 \mathrm{mmol} / 1$ AEBSF, $0.4 \mu \mathrm{mol} / 1$ aprotinin, $25 \mu \mathrm{mol} / 1$ bestatin, $12.5 \mu \mathrm{mol} / 1 \mathrm{E}-64 \mathrm{~A}, 10 \mu \mathrm{mol} / 1$ leupeptin hemisulphate, $5 \mu \mathrm{mol} / \mathrm{l}$ pepstatin) using a hand-held glass homogeniser. Samples were centrifuged at $13,000 \mathrm{~g}$ at $4^{\circ} \mathrm{C}$ for 5 min to remove insoluble material. The protein content of the clarified extracts was determined by a modification of the Lowry method [15]. Samples were diluted to a common concentration of $0.4 \mathrm{mg} / \mathrm{ml}$ in Laemmli buffer and $10 \mu \mathrm{g}$ total protein subjected to SDS-PAGE. The proteins were transferred to PVDF membrane (Immobilon) and blocked overnight at $4{ }^{\circ} \mathrm{C}(1 \%$ milk in TRIS-buffered saline with $0.25 \%$ Tween 20 ). Membranes were immunoblotted with antibody against GSK $3 \alpha$, GSK $3 \beta, p 110 \beta, \mathrm{PKC} \zeta$, insulin receptor $\beta$ subunit, Akt1, GLUT4, PGC1 or aP2 and washed with TBSE $(0.1 \%$ SDS, $5 \mathrm{mmol} / 1$ EDTA, $1 \%$ Triton X-100, 1\% deoxycholate in TRIS-buffered saline) followed by PBS wash buffer $(1 \%$ milk in phosphatebuffered saline with $0.2 \%$ Tween 20 ). Immunoreactive proteins were detected using horseradish-peroxidase-coupled secondary antibodies and enhanced chemilumines- cence (ECL) reagents according to the manufacturer's instructions (Amersham). ImageQuant software was used to quantify specific bands. For each antibody, control blots were performed, in which varying amounts of protein $(5$, 10 and $20 \mu \mathrm{g}$ ) were loaded on to the gel to ensure that the ECL signal changed in a linear manner. Primary and secondary antibody concentrations were also optimised.

Analysis of rat muscle and fat protein expression Muscle specimens were extracted and protein content determined as described above. We subjected $15 \mu \mathrm{g}$ total protein to SDS-PAGE and western blotting using antibodies directed against either GSK $3 \alpha$, GSK3 $\beta$, p85, GLUT 4, Akt1 or PGC1 as described above. As described above, control blots were performed, in which varying amounts of protein $(7.5,15$ and $30 \mu \mathrm{g})$ were loaded on to the gel to ensure that the ECL signal changed accordingly. Primary and secondary antibody concentrations were also optimised.

Statistical analysis All statistical analysis was carried out using Statistica statistical software (StatSoft, Tulsa, OK, USA). The data were normally distributed and there was no significant difference in the variances of the two groups. The significance of any difference between groups was examined by the Student's $t$-test and a $p$ value of less than 0.05 was considered statistically significant. Results in all cases are given as means \pm SEM.

\section{Results}

Subject characteristics Age-matched low-birthweight ( $n=$ $20)$ and control $(n=20)$ participants differed in birthweight by approximately $1 \mathrm{~kg}(2,702 \pm 202 \mathrm{~g}$ compared to $3,801 \pm$ $99 \mathrm{~g})$. The groups were similar with regard to current weight, body mass index, lean mass and fat mass; however current height was lower in the low-birthweight group (Table 1). Fasting plasma glucose was significantly higher in the low-birthweight group and 2-h post-load plasma glucose after an oral glucose tolerance test tended to be higher in the low-birthweight group (borderline significance, $p=0.07)$. There were no differences in fasting plasma insulin

Table 2 Expression of components of the insulin-signalling pathway in humans

\begin{tabular}{llc}
\hline Molecule & $\begin{array}{l}\text { Control } \\
\text { (\% control average) }\end{array}$ & $\begin{array}{l}\text { Low birthweight } \\
\text { (\% control average) }\end{array}$ \\
\hline PKC $\zeta$ & $100 \pm 4.6$ & $54 \pm 7.4^{* * *}$ \\
p110 $\beta$ & $100 \pm 5.6$ & $54 \pm 6.6^{* * *}$ \\
p85 $\alpha$ & $100 \pm 2.7$ & $82 \pm 5.1^{* *}$ \\
Glut 4 & $100 \pm 3.6$ & $81 \pm 4.0^{* * *}$ \\
GSK3 $\alpha$ & $100 \pm 9.5$ & $88 \pm 5.7$ \\
GSK3 $\beta$ & $100 \pm 3.9$ & $100 \pm 4.5$ \\
Akt1 & $100 \pm 6.5$ & $99 \pm 7.8$ \\
PGC1 & $100 \pm 8.5$ & $107 \pm 12.3$ \\
Insulin receptor & $100 \pm 9.5$ & $88 \pm 5.7$ \\
\hline
\end{tabular}

$* * * p<0.001 ; * * p<0.01$ 
Fig. 1 Insulin-signalling protein expression in low-birthweight humans (a), and rats (b). Protein expression was determined in human $(n=17-20)$ and rat $(n=8)$ samples by western blotting as described in Methods section. Black bars, control groups; grey bars, low-birthweight groups. Results are expressed as means \pm SEM. All results relate to muscle tissue with the exception of the rat p1 $10 \beta$ data that relate to adipocytes. No differences in the expression of GSK $3 \alpha$, GSK $3 \beta$, Akt1, Akt2, PGC1 or insulin receptor in muscle was observed between control and low-birthweight humans or rats.

${ }^{* * *} p<0.001 ; * * p<0.01 ; * p<0.05$
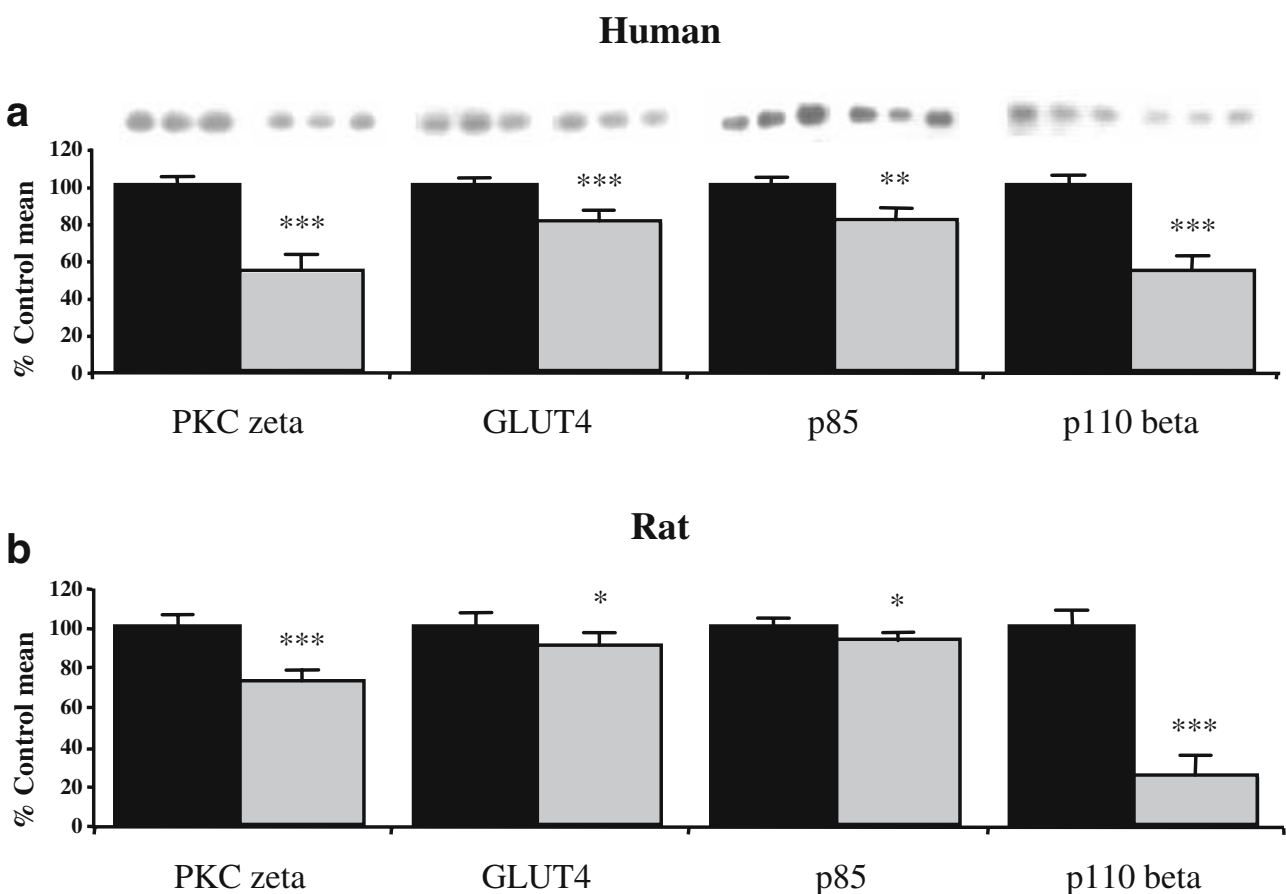

concentration $(53.5 \pm 9.3$ and $48.6 \pm 5.0 \mathrm{pmol} / 1$ for lowbirthweight and control respectively) or the 120-min plasma insulin concentration $(229.4 \pm 80.7$ and $165.2 \pm 25.6 \mathrm{pmol} / 1$ for low-birthweight and control respectively). Clamp studies showed no difference in whole-body insulin-stimulated glucose uptake between the two groups [12]. However, direct measurement of forearm muscle glucose uptake in a random subset of the subjects showed a blunted response to insulin in the low-birthweight group [13].

Muscle expression of insulin-signalling proteins in lowbirthweight subjects Vastus lateralis muscle from lowbirthweight subjects showed reduced expression $(p<0.001)$ of $\mathrm{PKC} \zeta$ compared to controls (Table 2). Low-birthweight subjects also had reduced expression of the p110 $\beta$ catalytic subunit of PI 3-kinase $(p<0.001)$, the $\mathrm{p} 85$ regulatory subunit of PI 3-kinase $(p<0.005)$ and GLUT4 $(p<0.001)$ (Table 2, Fig. 1). No changes in the muscle expression of GSK $3 \alpha$, GSK $3 \beta$, Akt1, PGC1 and the insulin receptor $\beta$ subunit were detected in the low-birthweight subjects (Table 2).

Table 3 Expression of components of the insulin-signalling pathway in rats

\begin{tabular}{lll}
\hline Molecule & $\begin{array}{l}\text { Control } \\
\text { (\% control average })\end{array}$ & $\begin{array}{l}\text { Low birthweight } \\
\text { (\% control average })\end{array}$ \\
\hline p85 $\alpha$ & $100 \pm 4.0$ & $93 \pm 3.8^{*}$ \\
Glut 4 & $100 \pm 5.1$ & $90 \pm 5.6^{*}$ \\
GSK3 $\alpha$ & $100 \pm 4.4$ & $95 \pm 5.3$ \\
GSK3 $\beta$ & $100 \pm 3.6$ & $102 \pm 3.7$ \\
Akt1 & $100 \pm 6.9$ & $114 \pm 10.9$ \\
PGC1 & $100 \pm 12.4$ & $93 \pm 12.4$ \\
\hline
\end{tabular}

${ }^{*} p<0.05$
Muscle expression of insulin-signalling proteins in lowprotein rats We have previously shown that the offspring of protein-restricted rat dams have a $28 \pm 6 \%$ reduction in expression of $\mathrm{PKC} \zeta$ in skeletal muscle compared to control offspring [7]. However, expression of the insulin receptor was similar in muscle of low-protein offspring compared to controls at 15 months of age [7]. In light of the striking similarity of these findings to those observed in human tissue as described above, we determined the expression of all the insulin-signalling components described above in muscle from the low-protein rat model of early growth restriction (Table 3). Expression of p85 was decreased in the LP rat muscle $(p<0.05)$ (Fig. 1). GLUT4 was also reduced $(p<0.05)$ in the low-protein offspring (Fig. 1). No changes in the muscle expression of GSK $3 \alpha, \operatorname{GSK} 3 \beta$, Akt1 and PGC1 were detected in the LP muscle (Table 3). In western blotting, $\mathrm{p} 110 \beta$ was undetectable in rat muscle tissue but very highly expressed in rat fatty tissue (Fig. 2).

Expression of aP2 in human muscle In light of the observation that $\mathrm{p} 110 \beta$ was present at high levels in rodent fat but undetectable in skeletal muscle, it was important to determine if the low levels of p $110 \beta$ detected in the human muscle biopsy could have resulted from contamination of these samples with fat. To investigate this, we blotted a

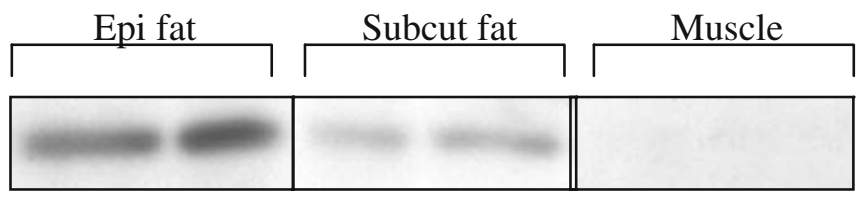

Fig. 2 Expression of $p 110 \beta$ in control rat tissues. Protein expression of $\mathrm{p} 110 \beta$ was determined in control rat epididymal fat, subcutaneous fat and soleus muscle as described (see Methods). Similar results were observed on seven separate occasions 


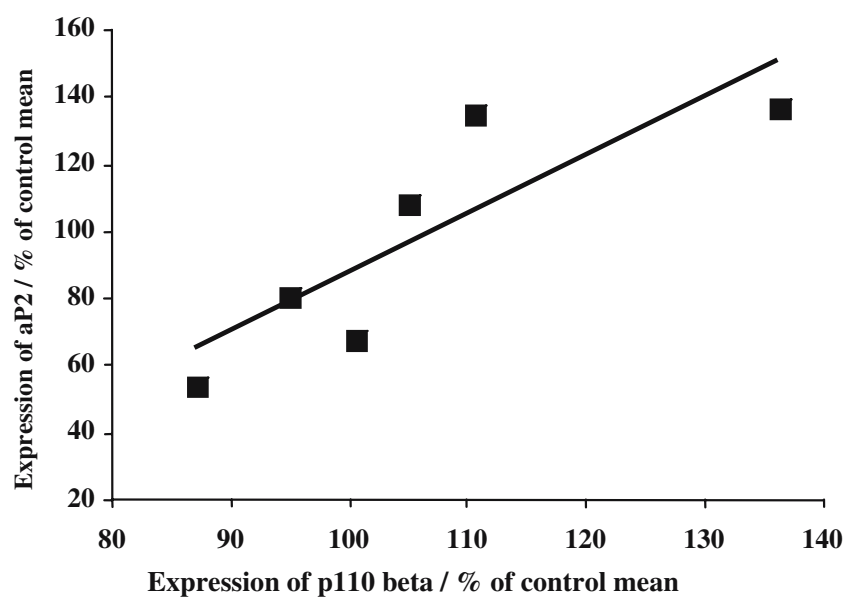

Fig. 3 Correlation between $a P 2$ and $p 110 \beta$ expression in human muscle samples. Expression of aP2 was determined in control human muscle samples $(n=6)$ as described (see Subjects, materials and methods). Results were correlated with $\mathrm{p} 110 \beta$ expression in corresponding samples. $p<0.05 ; r^{2}=0.72$

selection of the control human muscle samples with an antibody against the fatty acid binding protein aP2, which is specific to adipose tissue. In the human muscle samples, aP2 was detectable at a level of $3.3 \pm 0.5 \%$ of that observed in a sample of human adipose tissue. A strong positive correlation between the expression of $\mathrm{p} 110 \beta$ and $\mathrm{aP} 2$ was observed in the control muscle samples, suggesting that the $\mathrm{p} 110 \beta$ in the muscle biopsies could have resulted from adipose tissue contamination (Fig. 3). No difference in the amount of aP2 was observed between control and low-birthweight muscle samples $(3.3 \pm 0.3 \%$ compared to $2.6 \pm 0.8 \%)$.

\section{Discussion}

The association between low birthweight and the development of type 2 diabetes is well established [16]. Research interest is now focused on identifying the mechanistic basis of this relationship. As yet, no human studies have identified key molecules that may contribute to this relationship. Here, we provide novel evidence that defects in the expression of insulin-signalling intermediates in skeletal muscle may underlie and/or contribute to the previously reported muscle insulin resistance in these low-birthweight subjects [13]. It is interesting that the decreased muscle glucose uptake in response to insulin as measured directly across the forearm was not reflected by any detectable reduced insulin-stimulated peripheral glucose uptake at the level of whole-body glucose metabolism [12]. This indicates that the documented muscle insulin resistance and reduced expression of key proteins in the muscle insulin signal transduction system represent very early defects of metabolism linking low birthweight with overt insulin resistance and type 2 diabetes at a much later stage of life. Indeed, the low-birthweight subjects in this study were young, glucose-tolerant men with BMI, fat quantity and distribution, and insulin levels comparable to those of control subjects [12]. None of the subjects had a family history of diabetes. This reduces the possibility that the observed molecular defects originated from diabetes genes or were secondary to the effects of factors such as obesity, ageing, glucotoxicity or lipotoxicity.

No differences in insulin receptor expression were observed between muscle from control and low-birthweight men. This observation is consistent with studies of muscle from diabetic individuals that suggest that the molecular defect responsible for insulin resistance lies downstream of the insulin receptor [17]. The major proteins identified as being differentially expressed in control and low-birthweight muscle were $\mathrm{PKC} \zeta, \mathrm{p} 85 \alpha$ (regulatory subunit of PI 3-kinase), p110 $\beta$ (catalytic subunit of PI 3-kinase) and GLUT4. Similar reductions in the expression of PKC $\zeta$ [10] and $p 85[18]$ have been observed in the skeletal muscle of diabetic subjects, although in the latter case these subjects were also morbidly obese. There are no reports to date on the expression of $\mathrm{p} 110 \beta$ in muscle from diabetic patients compared to control subjects. Expression levels of GLUT4 have been reported to be similar in muscle from control and diabetic individuals $[19,20]$. However reduced levels of GLUT4 have been observed in adipose tissue from insulinresistant humans [21] and rodents [22]. Impaired regulation of GLUT4 gene expression in muscle tissue from lowbirthweight individuals has also been reported [23]. The absence of a difference in GLUT4 protein expression in muscle of overt diabetic individuals may be the result of compensatory mechanisms operating in the overt diabetic state. Alternatively, it may be explained by the heterogeneous nature and origin of type 2 diabetes, with different aetiological factors such as genetics, obesity and/or low physical activity underlying diabetes in some patients, and low birthweight and an adverse intrauterine environment underlying diabetes in other distinct groups of patients. Thus, the molecular mechanisms by which each of these aetiological factors is associated with insulin resistance and type 2 diabetes may be different, and if this is the case, it would be very important to study distinct and well-characterised homogenous pre-diabetic subgroups (low-birthweight subjects, first degree relatives etc.) to identify the unique mechanisms by which the different aetiological factors cause diabetes in man. It is possible that the changes in protein expression observed by us are secondary to the increased fasting plasma glucose observed in the lowbirthweight subjects. However this would seem unlikely, given that the increase in fasting plasma glucose in the lowbirthweight group is small.

The absence of the p110 $\beta$ catalytic subunit of PI 3kinase in rat skeletal muscle tissue was an unexpected observation. PI 3-kinase is a hetero-dimeric enzyme consisting of an adapter/regulatory subunit termed p85 and a catalytic subunit termed p110 [24]. Several isoforms of the catalytic subunit have been identified [24]. However, the functional significance of these is not well understood. The $p 110 \beta$ subunit is highly expressed in rat adipose tissue, suggesting that it may be important in mediating aspects of insulin action in fat cells such as anti-lipolysis. 
The abundance of aP2 was positively correlated with the expression of $\mathrm{p} 110 \beta$ in the muscle biopsy samples. This suggests that the observed difference in p110 $\beta$ between the control and low-birthweight muscle samples resulted from differential expression of $\mathrm{p} 110 \beta$ in the fat tissue present in the muscle biopsies. This finding is consistent with the observed reduction in $\mathrm{p} 110 \beta$ in adipose tissue from low-protein rat offspring [8]. These observations suggest that insulin-signalling defects in these subjects may extend to fat tissue. These findings may also partially account for the observed decreased expression of GLUT4 in the low-birthweight group. The observed reduction of $\mathrm{p} 110 \beta$ expression may also be attributed to the reduced expression of $\mathrm{p} 85$. Previous studies have suggested that the interaction between the catalytic and regulatory subunits is important for the stability of the p110 catalytic subunit $[25,26]$.

Our observations suggest for the first time that poor early growth in humans is associated with changes in protein expression of components of the insulin-signalling pathway. The specific changes observed are strikingly similar to those observed by us in a nutritional model of early growth restriction that also develops diabetes. They therefore provide compelling evidence that the fetal environment plays a critical role in determining future susceptibility to type 2 diabetes. The changes in expression precede the development of overt whole-body insulin resistance and glucose intolerance, and therefore provide a protein fingerprint that is indicative of future disease. Such a molecular fingerprint, if extended to a clinically accessible tissue, would make targeted intervention strategies a realistic possibility.

Acknowledgements We thank Marianne Modest, Susanna Riemar, Adrian Wayman and Ann Flack for expert technical assistance. We are grateful to Professor Nick Hales and Professor Steve O'Rahilly for helpful discussions. This work was supported by the Wellcome Trust, the British Heart Foundation, the Medical Research Council, the Parthenon Trust, the Danish Diabetes Association and the Novo Nordisk Research Foundation.

\section{References}

1. Hales CN, Barker DJ (2001) The thrifty phenotype hypothesis. Br Med Bull 60:5-20

2. Hattersley AT, Beards F, Ballantyne E, Appleton M, Harvey R, Ellard S (1998) Mutations in the glucokinase gene of the foetus result in reduced birth weight. Nat Genet 19:268-270

3. Poulsen P, Vaag AA, Kyvik KO, Moller Jensen D, BeckNielsen H (1997) Low birth weight is associated with NIDDM in discordant monozygotic and dizygotic twin pairs. Diabetologia 40:439-446

4. Bo S, Cavallo-Perin P, Scaglione L, Ciccone G, Pagano G (2000) Low birth weight and genetic abnormalities in twins with increased susceptibility to Type 2 diabetes mellitus. Diabet Med 17:365-370

5. Ravelli AC, Van der Meulen JH, Michels RP et al (1998) Glucose intolerance in adults after prenatal exposure to famine. Lancet 351:173-177

6. Hales CN, Ozanne SE (2003) For debate: fetal and early postnatal growth restriction lead to diabetes, the metabolic syndrome and renal failure. Diabetologia 46:1013-1019
7. Ozanne SE, Olsen GS, Hansen LL et al (2003) Early growth restriction leads to down regulation of protein kinase $\mathrm{C}$ zeta and insulin resistance in skeletal muscle. J Endocrinol 177:235-241

8. Ozanne SE, Nave BT, Wang CL, Shepherd PR, Prins J, Smith GD (1997) Poor fetal nutrition causes long-term changes in expression of insulin signalling components in adipocytes. Am J Physiol Endocrinol Metab 273:E46-E51

9. Ozanne SE, Dorling MW, Wang CL, Nave BT (2001) Impaired PI 3-kinase activation in adipocytes from early growth-restricted male rats. Am J Physiol Endocrinol Metab 280:E534E539

10. Farese RV (2002) Function and dysfunction of aPKC isoforms for glucose transport in insulin-sensitive and insulin-resistant states. Am J Physiol Endocrinol Metab 283:E1-E11

11. White MF (1994) The IRS-1 signalling system. Curr Opin Genet Dev 4:47-54

12. Jensen CB, Storgaard H, Dela F, Holst JJ, Madsbad S, Vaag AA (2002) Early differential effects of insulin secretion and action in 19-year-old Caucasian men who had a low birth weight. Diabetes 51:1271-1280

13. Hermann TS, Rask-Madsen C, Ihlemann N et al (2003) Normal insulin-stimulated endothelial function and impaired insulinstimulated muscle glucose uptake in young adults with low birthweight. J Clin Endocrinol Metab 88:1252-1257

14. Snoeck A, Remacle C, Reusens B, Hoet JJ (1990) Effect of a low protein diet during pregnancy on the fetal rat endocrine pancreas. Biol Neonate 57:107-118

15. Schacterle GR, Pollack RL (1973) A simplified method for the quantitative assay of small amounts of protein in biologic material. Anal Biochem 51:654-655

16. Newsome CA, Shiell AW, Fall CH, Phillips DI, Shier R, Law CM (2003) Is birth weight related to later glucose and insulin metabolism? - a systematic review. Diabet Med 20:339-348

17. Krook A, Bjornholm M, Galuska D et al (2000) Characterization of signal transduction and glucose transport in skeletal muscle from type 2 diabetic patients. Diabetes 49:284-292

18. Goodyear LJ, Giorgino F, Sherman LA, Carey J, Smith RJ, Dohm GL (1995) Insulin receptor phosphorylation, insulin receptor substrate-1 phosphorylation, and phosphatidylinositol 3-kinase activity are decreased in intact skeletal muscle from obese subjects. J Clin Invest 95:2195-2204

19. Handberg A, Vaag A, Damsbo P, Beck-Nielsen H, Vinten J (1990) Expression of insulin regulatable glucose transporters in skeletal muscle from type 2 (non-insulin-dependent) diabetic patients. Diabetologia 33:625-627

20. Pederson O, Bak JF, Anderson PH et al (1990) Evidence against altered expression of GLUT1 or GLUT4 in skeletal muscle of patients with obesity or NIDDM. Diabetes 39:865870

21. Sinha MK, Raineri-Maldonado C, Buchanan C et al (1991) Adipose tissue glucose transporters in NIDDM. Decreased levels of muscle/fat isoform. Diabetes 40:472-477

22. Shepherd PR, Kahn BB (1999). Glucose transporters and insulin action-implications for insulin resistance and diabetes mellitus. N Engl J Med 341:248-257

23. Jaquet D, Vidal H, Hankard P, Czernichow P, Levy-Marchal C (2001) Impaired regulation of glucose transporter 4 gene expression in insulin resistance associated with in utero undernutrition. J Clin Endocrinol Metab 86:3266-3271

24. Shepherd PR, Withers DJ, Siddle K (1998) Phosphoinositide 3kinase: the key switch mechanism in insulin signalling. Biochem J 333:471-490

25. Yu J, Zhang Y, Mcllroy J, Rordorf-Nikolic T, Orr GA, Backer JM (1998) Regulation of the p85/p110 phosphatidylinositol 3'kinase: stabilization and inhibition of the p110alpha catalytic subunit by the p85 regulatory subunit. Mol Cell Biol 18:13791387

26. Ueki K, Fruman DA, Brachmann SM, Tseng YH, Cantley LC, Kahn CR (2002) Molecular balance between the regulatory and catalytic subunits of phosphoinositide 3-kinase regulates cell signalling and survival. Mol Cell Biol 22:965-977 